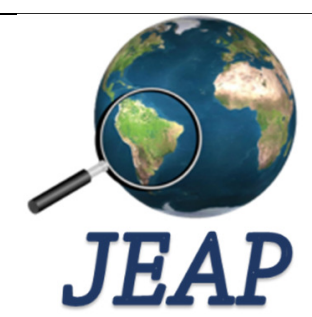

ISSN: 2525-815X

\section{Journal of Environmental} Analysis and Progress

Journal homepage: www.ufrpe.br/jeap http://dx.doi.org/10.24221/jeap.2.1.2017.1128.87-97

\title{
Diagnóstico da vegetação remanescente de Mata Atlântica e ecossistemas associados em espaços urbanos
}

\section{Vegetation diagnosis of remaining Atlantic Forest and associated ecosystems in urban spaces}

Mayara de Sousa Dantas ${ }^{\mathrm{a}}$, Nadjacleia Vilar Almeida ${ }^{\mathrm{a}}$, Iara dos Santos Medeiros ${ }^{\mathrm{a}}$, Milena Dutra da Silva ${ }^{b}$

${ }^{\text {a }}$ Universidade Federal da Paraíba, Campus IV/Litoral Norte/Departamento de Engenharia e Meio Ambiente. Av. Santa Elizabete, 160, Rio Tinto, Paraíba. CEP: 58297-000. E-mail: mayaradantas-@outlook.com, nadjageo@gmail.com, iara.s.medeiros@hotmail.com.

${ }^{\mathrm{b}}$ Universidade Federal de Alagoas, Campus Arapiraca/Penedo. Av. Beira Rio, Penedo, Alagoas. CEP: 57200-000. Email:milena.silva@penedo.ufal.br.

\section{A R T I C L E I N F O}

Recebido 28122016

Aceito 25012017

Publicado 31012017

\begin{abstract}
A B S T R A C T
Habitat loss and fragmentation are a major threat to biodiversity conservation and environmental services provided. Through Landscape metrics, changes in vegetation remnant pattern patterns can be measured and monitored. The present research aimed to perform the Diagnosis of the Remaining Vegetation of Atlantic Forest and Associated Ecosystems in Urban Spaces of João Pessoa-Paraíba. For this purpose, RapidEye satellite images were obtained from GeoCatálogo of the Ministry of the Environment, corresponding to the year 2015, supporting the elaboration and editing of vector data. The landscape metrics were calculated using the V-LATE extension (Vector Based Landscape Analysis Tools Extension), a free version for study. Thematic maps of edge and the average index of form were elaborated, thus generating the environmental diagnosis of the vegetation. The remaining vegetation of Atlantic forest is fragmented in 48 spots, with reduced area and a high density of edges. The mean index of form was equivalent to 2,698, evidencing that the spots had more linear forms, often, not containing core areas inside the fragments. It is concluded that the remnant vegetation of Atlantic forest in João Pessoa presents a form and structure that raise a worrisome degree of environmental fragility, making it necessary to expand the inspections in the area, as well as the implementation of environmental recovery and preservation measures.
\end{abstract}

Keywords: Landscape ecology, landscape indices, fragmentation.

\section{R E S U M O}

A perda e a fragmentação de habitats constituem uma das principais ameaças a conservação da biodiversidade e aos serviços ambientais prestados. Por intermédio das métricas de Paisagem, as mudanças nos padrões da mancha de remanescentes vegetacionais podem ser mensuradas e monitoradas. A presente pesquisa objetivou realizar o Diagnóstico da Vegetação Remanescente de Mata Atlântica e Ecossistemas Associados em Espaços Urbanos de João Pessoa-Paraíba. Para tal, foram obtidas imagens de satélite RapidEye, adquiridas no GeoCatálogo do Ministério do Meio Ambiente, correspondente ao ano de 2015, dando suporte a elaboração e edição de dados vetoriais. O cálculo das métricas de paisagem foi realizado na extensão VLATE (Vector Based Landscape Analysis Tools Extension), versão gratuita para estudo. Feito isto, foram elaborados mapas temáticos de borda e o de índice médio de forma, gerando assim o diagnóstico ambiental da vegetação. A vegetação 
remanescente de mata atlântica apresenta-se fragmentada em 48 manchas, com área reduzida e uma alta densidade de bordas. O índice médio de forma foi equivalente a 2,698, evidenciando que as manchas apresentaram formatos mais lineares, muitas vezes, não contendo áreas-núcleo no interior dos fragmentos. Conclui-se que a vegetação remanescente de mata atlântica em João Pessoa apresentam forma e estrutura que suscitam preocupante grau de fragilidade ambiental, fazendo-se necessária a ampliação das fiscalizações na área, bem a implementação de medidas de recuperação e preservação ambiental.

Palavras-Chave: Ecologia da paisagem, índices de paisagem, fragmentação.

\section{Introdução}

O bioma Mata Atlântica, originalmente, ocupava $15 \%$ do território brasileiro, formado por um conjunto de florestas diversas como a Floresta Ombrófila Densa, Floresta Ombrófila Mista, Floresta Estacional decidual e Semidecidual, os campos de altitude e ecossistemas associados, como os manguezais, restingas, brejos interioranos, ilhas costeiras e oceânicas (Fundação SOS Mata Atlântica, 2009).

Desde o início da colonização do Brasil, o bioma Mata Atlântica vem passando por diversas fases de conversão da vegetação nativa para usos do solo de maior interesse econômico. O histórico desse bioma acompanhou a lógica dominante em mais de 500 anos, na qual o "progresso" exigia a destruição das matas e a separação entre o homem e a natureza, com priorização de culturas extrativista e agropecuária, bem como a urbanização (Fundação SOS Mata Atlântica, 2009). Essas pressões configuram um cenário de redução da Mata Atlântica que, já na década de 2000, contabilizava apenas $7 \%$ da sua cobertura vegetal.

A Mata Atlântica foi considerada, através de um decreto na Constituição Federal de 1988, Reserva da Biosfera pela UNESCO e Patrimônio Natural (Fundação SOS Mata Atlântica, 2009). Os motivos para isto foi o alto nível de diversidade biológica, que faz da Mata Atlântica um dos maiores repositórios de biodiversidade do planeta e com os mais altos níveis de endemismos. À medida em que a Mata Atlântica é considerada um dos biomas mais importantes, é também um dos mais ameaçados do planeta e, nesse sentido, se faz necessária uma maior proteção de seus indivíduos (Varjabedian, 2010, p.147).

Aproximadamente $72 \%$ da população brasileira vive na Mata Atlântica. Com base nas estimativas do IBGE (2010), são mais de 145 milhões de habitantes em 3.429 municípios, correspondendo a $61 \%$ dos existentes no Brasil. Destes, 2.481 municípios possuem a totalidade dos seus territórios inseridos neste bioma e mais 948 municípios estão parcialmente inclusos.

Entre os municípios citados anteriormente destaca-se a cidade de João Pessoa, capital do estado da Paraíba, no qual, segundo a fundação
Fundação SOS Mata Atlântica (2014), restam 12\% de remanescentes de Mata Attântica na capital Paraibana João Pessoa- PB, Brasil.

Nas últimas décadas, de 1980 a 2010, a cidade vem experimentando um crescimento vertiginoso e desenfreado, com percentual de urbanização de quase $100 \%$ para o ano de 2015 (Silva et al., 2016; IBGE, 2015).

Nas últimas décadas, a fragmentação do bioma Mata Atlântica, na cidade de João Pessoa, aumentou, restando apenas $12 \%$ de remanescentes na cidade; muitas vezes, tais fragmentos vegetacionais, não apresentam uma área mínima para sobrevivência das espécies (Fundação SOS Mata Atlântica, 2014). Como resultado, vão sendo criados fragmentos de vegetação na cidade, ocasionando um fenômeno bastante conhecido e prejudicial para toda comunidade biológica: a fragmentação florestal. Trata-se de um processo no qual uma área extensa e conectada é retalhada, dando lugar a pequenas manchas vegetacionais de tamanho reduzido. Esse fenômeno pode ser ocasionado por causas naturais, entretanto, nas últimas décadas, a fragmentação de origem antrópica tem sido a mais influente na transformação da paisagem em João Pessoa (Silva et al., 2015).

A fragmentação de habitats tem efeitos diretos nas relações ecológicas. O surgimento de barreiras, sejam elas naturais ou antrópicas, traz consigo o isolamento propriamente dito, a diminuição de área de vida utilizável, a diminuição do fluxo gênico, o isolamento reprodutivo e, consequentemente, a perda da diversidade genética.

Essas mudanças geram um efeito "cascata", na qual, com a perda de espécies, relações de interação são afetadas. A vegetação deixa de exercer as funções ambientais, tais como, amenização do microclima local, regulação do ciclo hidrológico, manutenção dos recursos naturais, proteção de encostas, contribuição na produção de oxigênio e captura de $\mathrm{CO} 2$, contribuição à variabilidade genética, decomposição de resíduos, regulação da composição química dos oceanos, função de filtros, no caso das matas ciliares, entre outros (Bierregaard et al., 1992; Primack, 1993; 
Campanilli et al., 2010). Existem, também, efeitos indiretos, como a perda da beleza cênica das paisagens, atribuídas à vegetação.

Devido às importantes funções ambientais, sociais e econômicas prestadas, a cobertura vegetal brasileira tem sido amparada por um vasto arcabouço jurídico (Rudolpho et al., 2013).

O Ministério do Meio Ambiente (MMA) define as áreas verdes urbanas "como um conjunto de áreas intraurbanas que apresentam cobertura vegetal, arbórea, arbustiva ou rasteira, e que contribuam de modo significativo para a qualidade e o equilíbrio ambiental das cidades".

$\mathrm{Na}$ descrição do Conselho Nacional do Meio Ambiente-CONAMA (Art. $8^{\circ}, \S 1^{\circ}$ da Resolução Conama 369/2006) e do MMA as áreas verdes colaboram diretamente para uma melhor qualidade de vida urbana e, segundo o Conama, essas áreas devem ser de propriedade pública (Anjos, 2014). No código florestal brasileiro (Art. $3^{\circ}$, XX, Lei $\left.{ }^{\circ} 12.651 / 2012\right)$ definem as áreas verdes urbanas como:

"Espaços públicos ou privados, com predomínio de vegetação, preferencialmente nativa, natural ou recuperada, previstos no Plano Diretor, nas Leis de zoneamento urbano e uso do solo do município, indisponíveis para construção de moradias, destinados aos propósitos de recreação, lazer, melhoria da qualidade ambiental urbana, proteção de bens e manifestações culturais." (Código Florestal, Art. $3^{\circ}$, XX, Lei $n^{\circ} 12.651 / 2012$ ).

Entretanto, na maioria das vezes, nem mesmo o reconhecimento científico sobre a importância da cobertura vegetal e a existência do aparato legislativo tem garantido sua preservação (Rudolpho et al., 2013).

Para fins de diagnóstico e monitoramento da biodiversidade do bioma Mata Atlântica a realização de estudos, alicerçados em Ecologia da Paisagem e métodos e técnicas em geoprocessamento, poderão ser importantes ferramentas auxiliares.

Pellegrino et al. (2006) afirmam que a ecologia da paisagem, o sensoriamento remoto e o Sistema de Informação Geográfica (SIG) representam um grande avanço de métodos e técnicas aplicados no diagnóstico ambiental, como medida de solucionar este problema possibilitando assim um estudo local, em escala espacial e global reduzindo a dependência dos levantamentos de campo, além de permitir uma análise integrada de características como os padrões de fragmentação isolamento e conectividade ocasionadas pelas atividades humanas e como estas atividades influenciam nos processos ecológicos. Os resultados desses estudos são obtidos pelas métricas de paisagem.

A ecologia de paisagem é o estudo espacial e visual do ambiente; proporciona a conexão analítica entre os sistemas naturais e antrópicas, possibilitando o entendimento das interrelações entre o homem e suas atividades, em uma visão integradora e sistêmica (Porto, 2004). O termo Paisagem foi introduzido no meio científico pelo geógrafo e naturalista Alexander Von Humboldt. Outro autor de destaque, Carl Troll, que, juntamente com outros pesquisadores, deu um impulso para o surgimento desta abordagem geográfica (Ecopaisagem, 2014).

A Ecologia da Paisagem é considerada um termo relativamente novo na área da ecologia, não possuindo uma base comum e, ainda, em busca de um embasamento teórico.

A Ecologia da Paisagem apresenta uma bifurcação de visões ou abordagens. A primeira visão corresponde a uma concepção geográfica que enfatiza a avaliação em amplas escalas, a interrelação homem-ambiente, onde ele (o homem) está inserido. Essa visão Geográfica tem como suporte as áreas da geografia e outras disciplinas que se preocupam com a gestão e o planejamento do território, e a consequente ocupação do espaço (Metzger, 2001; Farina, 2006; Bastian, 2001).

A segunda abordagem da Ecologia da Paisagem, conhecida como abordagem Ecológica, deriva da adaptação da teoria da Biogeografia de Ilhas. Essa abordagem surgiu em um workshop formado por ecólogos americanos na década de 1980. Levam em conta pequenas escalas, dando ênfase a espécie em estudo; a abordagem Ecológica busca entender como os elementos da paisagem estão dispostos espacialmente, visando compreender as implicações de determinado padrão da paisagem (Metzger, 2001; Nucci, 2007).

Em uma perspectiva holística, Metzger propôs uma fusão das duas osaico heterogêneo formado por unidades interativas, sendo esta heterogeneidade existente para pelo menos um fator; segundo um observador e numa determinada escala de observação" (Metzger, 2001, p. 4).

Segundo Forman \& Godron (1986), o estudo da ecologia de paisagem pode ser dividido em três aspectos: 1) Estrutura, 2) Função, e 3) Desenvolvimento e Mudança. A presente pesquisa dá ênfase à estrutura da mancha da vegetação.

$\mathrm{O}$ conceito de estrutura da paisagem, conforme Dollinger (2002), é relativamente novo dentro da ecologia de paisagens; trata-se do estudo 
do mosaico da paisagem que aparece como padrão e ordenamento.

A estrutura e padrão espacial da paisagem são considerados como manifestações espaciais/temporais de processos que ocorrem em diferentes planos de escala (Forman, 1995; O’Neil, 2001). Processos e estruturas encontram-se em um jogo alternado de causa e consequência, isto significa que os processos que ocorrem na paisagem geram padrões e estruturas, os quais, concomitantemente, são, também, influenciados e guiados pelas estruturas espaciais dominantes.

Para a avaliação analítica da estrutura da paisagem foi criado um conjunto de métodos, designados medidas de estrutura da paisagem, considerado como o coração metodológico do conceito de estrutura da paisagem (Lang \& Blaschke, 2000).

Conforme Lang (2009, p.237), "a análise da estrutura da paisagem com subsídios das métricas de paisagem ocorre em três níveis: no nível da mancha; no nível da classe; e no nível de toda a paisagem". Com o intuito de se quantificar, os padrões espaciais e o ordenamento territorial, surgem às medidas de estrutura de paisagem, as métricas, elas nada mais são do que um conjunto de métodos de geoprocessamento, que atende a trabalhos de planejamento da paisagem em grandes áreas, tendo um papel de relevância nesse tipo de análise. Tais medidas buscam entender as relações de causa entre padrões e processos na paisagem (Turner et al., 1989; Forman, 1995).
As métricas de paisagem são algoritmos que quantificam características espaciais dos fragmentos isoladamente em conjunto ou de todo mosaico da paisagem (Couto, 2004). A partir do cálculo das métricas podem-se inferir sobre a qualidade da mancha estes dados são de extrema importância principalmente em áreas com intensa pressão antrópica. As atividades como supressão da vegetação, decorrentes da demanda por solo desnudo, fazem com que as manchas ou fragmentos exibam padrões que através de análises quali-quantitativas o pesquisador poderá inferir sobre a qualidade da mancha.

Diante disso, o objetivo deste trabalho é o diagnóstico da vegetação remanescente de mata atlântica e ecossistemas associados em espaços urbanos de João Pessoa-PB.

\section{Material e Métodos}

Área de estudo

O "município de João Pessoa situa-se no extremo leste do Estado da Paraíba entre as coordenadas $7^{\circ} 14^{\prime} 29^{\prime \prime}$ de Latitude sul $34^{\circ} 58^{\prime} 36^{\prime \prime}$ de Longitude Oeste e $7^{\circ} 03^{\prime} 18^{\prime \prime}$ de latitude sul $34^{\circ}$ 47’36', na microrregião de João Pessoa e na mesorregião da Mata Paraibana (Figura 1). Limitase ao Sul com o município do Conde, ao Oeste com os municípios Bayeux e Santa Rita, ao Norte com o município de Cabedelo e ao Leste com o Oceano Atlântico (Silva et al., 2016).

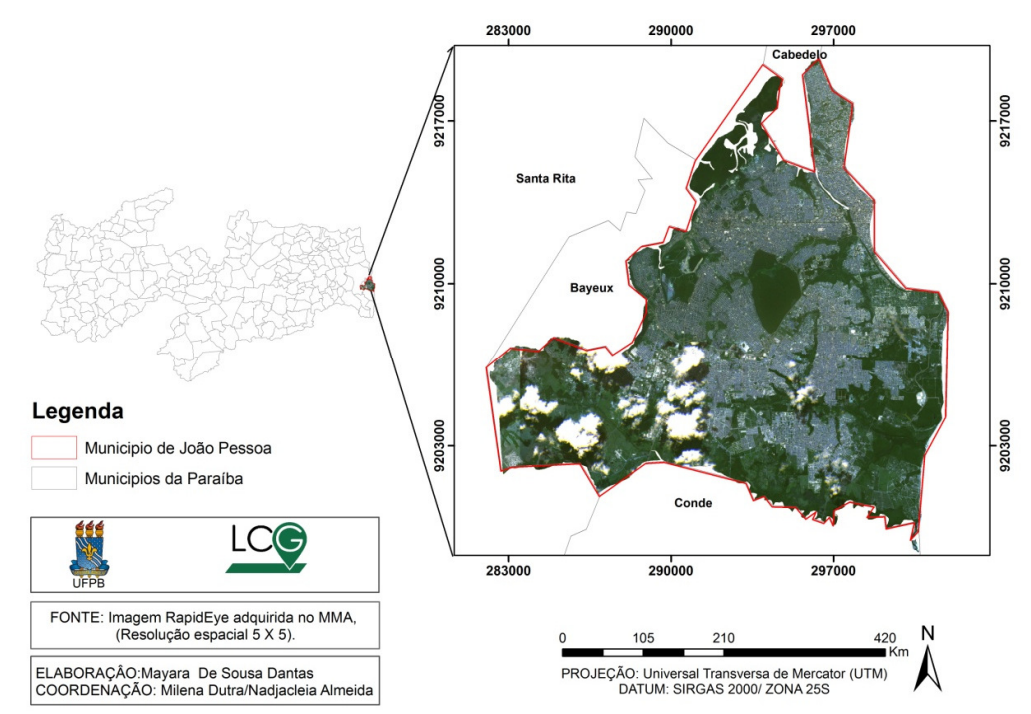

Figura 1. Localização do Município de João Pessoa, no estado da Paraíba, Brasil.

O município abrange uma área territorial de $211,475 \mathrm{~km}^{2}$ com, aproximadamente, 723,515 mil habitantes (IBGE, 2010).

O clima é quente e úmido, classificado segundo a classificação climática de Koppen como
A's, com chuvas de outono e inverno (Paraíba, 1985). A temperatura média anual fica em torno dos $26^{\circ} \mathrm{C}$. O relevo é planície e a vegetação representada pelo bioma Mata Atlântica. A 
economia gira em torno de serviços, indústria comércio e o turismo.

\section{Procedimentos técnicos}

A metodologia foi dividida em duas etapas, a saber, aquisição e edição dos dados vetoriais e cálculo das métricas. A análise nessa pesquisa foi efetuada em nível de classe, vegetação remanescente de Mata Atlântica do Município de João Pessoa, Paraíba.

\section{Aquisição e edição de imagens de satélite}

Para o desenvolvimento da pesquisa foram utilizados os dados vetoriais correspondentes às áreas verdes de João Pessoa, adquiridos junto ao Laboratório de Ambiente Urbano e Edificado (LAURBE), situado no Campus I da UFPB. Posteriormente, efetuou-se a aquisição da imagem do satélite RapidEye adquirida através do geoCatálogo do Ministério do Meio Ambiente (http://geocatalogo.mma.gov.br/index.jsp),

correspondente ao ano de 2015. Esta imagem foi recortada de acordo com o limite da área de estudo, dando suporte à edição e atualização dos dados vetoriais por imagem, haja vista que os dados foram obtidos no LAURBE. Isto se fêz necessário pelo fato destas àreas serem anteriormente manchas de vegetação. Considerando o ano de 2015, elas apresentaram redução na sua área ou foram suprimidas. Em seguida, os dados vetoriais foram unidos em uma única camada, a fim de analisar a vegetação em nível de classe. Em seguida foi realizada a etapa de cálculo das métricas da paisagem na extensão V-LATE (vector-based landscape analysis tools extension, do Arcgis - versão gratuita para estudo). As métricas utilizadas foram área, borda, forma e áreas-núcleo. Para a classe de vegetação remanescente, o cálculo de área foi efetuado aplicando a fórmula extraída de Lang \& Blaschke (2000):

$\operatorname{AREA}=0,5 \cdot \sum\left(x_{i+1}-x_{i}\right)\left(y_{i+1}+y_{i} \quad\right.$ Equação 1

onde: $\mathrm{x}$ e $\mathrm{y}$-coordenadas do i-ésimo ponto de apoio do polígono.

\section{Cálculo da borda} a Equação 2.

O cálculo da borda foi realizado aplicando

$$
\text { PERIM }=\sum \sqrt{ }\left(x_{i+1}-x_{i}\right)^{2}+\left(y_{i+1}-y_{i}\right)^{2} \quad \text { Equação } 2
$$

onde: x e y são coordenadas do $i$-ésimo ponto de apoio do polígono.
Cálculo da forma

SHAPE $=\frac{p}{2 \sqrt{\pi} \cdot a}$ Equação 3

onde: $\mathrm{p}=$ perímetro; $a=$ área

\section{Cálculo do Cority}

$$
C Y=\frac{N P-N_{C A I=0}}{N C A}
$$

Equação 4

onde: $C Y=$ Cority; $N_{C A l=0}$

\section{Resultados e Discussão \\ Métricas de área}

Ao analisar a vegetação de João Pessoa, considerando o ano de 2015, constatou-se que a área total da classe vegetação remanescente foi de $68,15 \mathrm{~km}^{2}$, correspondendo a 32,23\% da área total do município. Ressalta-se que essa vegetação encontra-se fragmentada em 48 manchas, de diferentes tamanhos, formas e níveis de susceptibilidade (vinculadas à presença de áreas núcleos, na qual a ausência dessas é interpretada como apresentando elevado grau de susceptibilidade).

A redução da vegetação no município nas últimas quatro décadas pode ser atribuída à demanda por solo desnudo para implantação de equipamentos urbanos, como indústrias, residências, entre outros. Estas transformações são ocasionadas, em grande parte, pela especulação e déficit imobiliário (Anjos, 2014).

Os maiores fragmentos vegetacionais encontram-se ao norte, no bairro Alto do Céu; ao centro, na Mata do Buraquinho, delimitada pelos bairros do Varjão, Jaguaribe, Água-fria, São Paulo, Bancários, Castelo Branco e Torre; ao oeste, nos bairros Ilha do Bispo e Cruz das Armas; ao leste, nos bairros Castelo Branco, Altiplano e Bancários; ao sudeste, no bairro Costa do Sol; e na porção sul, em Muçumagro, Gramame e Mumbaba (Figura 2).

Destaca-se que os fragmentos de maior área de cobertura estão inseridos em importantes bacias hidrográficas no município, a saber: Bacia hidrográfica $(\mathrm{BH})$ do Rio Paraíba (fragmento vegetacional ao norte), $\mathrm{BH}$ do Rio Jaguaribe (fragmento vegetacional Mata do Buraquinho), $\mathrm{BH}$ do Rio Cuiá (fragmento vegetacional na porção sudeste), BH do Rio Gramame (fragmento vegetacional ao sul e sudoeste), entre outros.

Os menores fragmentos encontram-se pulverizados nos espaços intraurbanos, sobretudo nos bairros do Bessa, Jardim Oceania, Aeroclube, Altiplano, Cabo Branco, Bairro dos Ipês, João Agripino, São José, Jardim Veneza, Ernane Sátiro e Oitizeiro (Figura 2). Segundo Costa (2003), nos 
"fragmentos com área reduzida" as espécies existentes tendem a apresentar uma maior suscetibilidade à extinção, pois se constituem em populações com baixa variabilidade genética, haja vista o número reduzido de recursos e indivíduos na mancha.

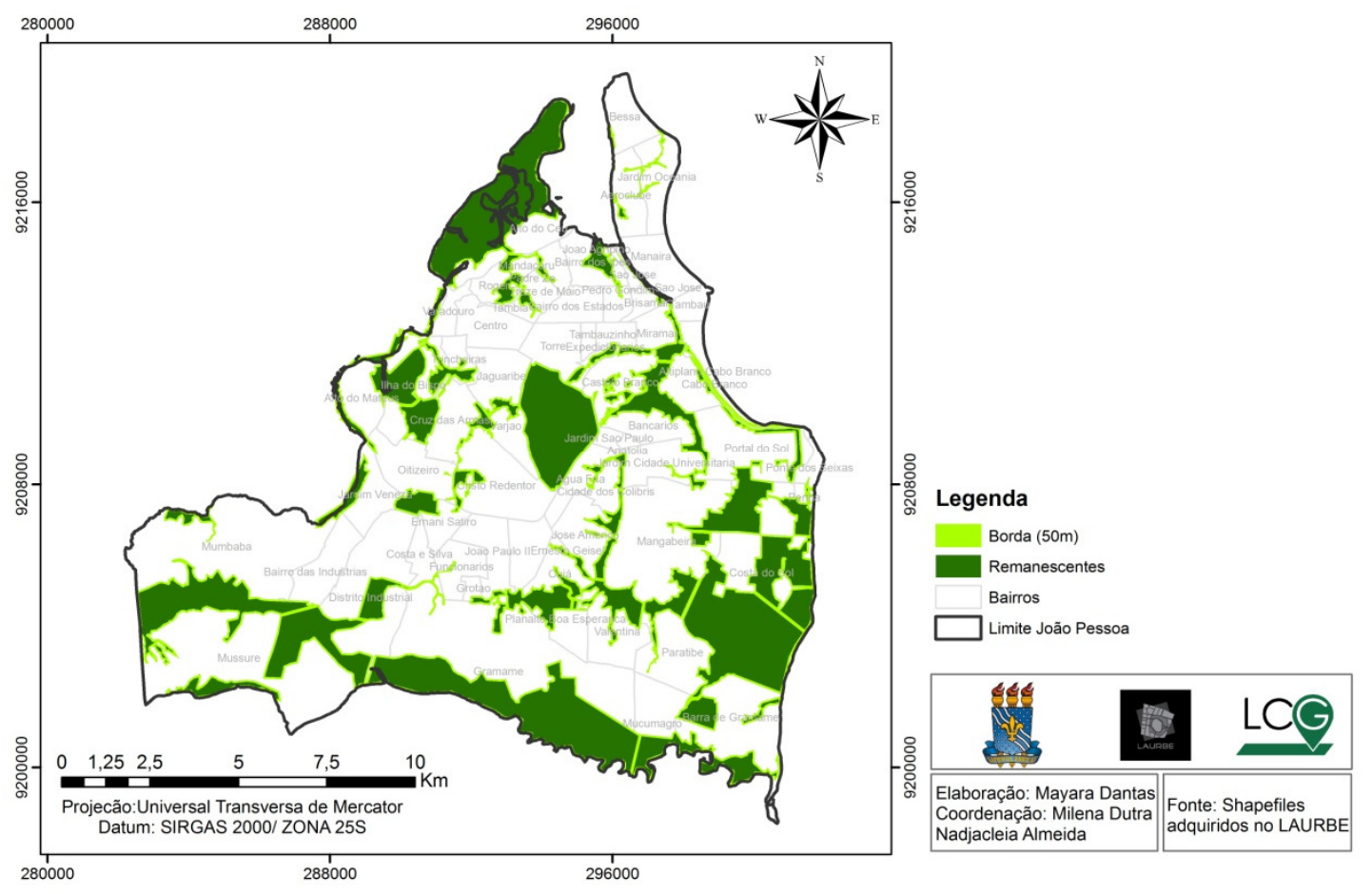

Figura 2. Distância da borda de $50 \mathrm{~m}$ para a classe Vegetação Remanescente de Mata Atlântica, em João Pessoa, Paraíba, Brasil.

Quanto à redução da área de vegetação, como demonstrado em estudos de Formam et al. (1976), Seagle (1986) e Saunders et al. (1991), existem implicações na redução da riqueza das espécies, de modo proporcional à redução da mancha. Existem, ainda, implicações na disponibilidade de recursos, que vão se tornando escassos, e, em consequência disto, têm-se a intensificação de competições intra e interespecíficas das espécies nas manchas.

\section{Métricas relativas à borda}

Os valores do total das somas das bordas (TE) das manchas de vegetação remanescentes equivalem a 424,31 km, e o comprimento médio da borda (MPE), a 8,84. Valores elevados sugerem uma maior superfície de contato com a matriz exterior que, no caso deste estudo, corresponde à malha urbana (Vidolin, Biondi \& Wandenbruck, 2011).

As características de borda podem afetar os organismos do fragmento, fazendo que alguns organismos evitem o ambiente de borda tendo em vista a mudança brusca nas condições bióticas e abióticas. Entre estas alterações estão os efeitos sobre o microclima, como o aumento da temperatura, luminosidade e redução da umidade, além de ruídos e uma maior exposição aos ventos aos quais as espécies de interior não estão adaptadas. No entanto, algumas espécies podem se beneficiar dessas condições de borda e aumentar sua densidade, tornando-se um elemento de perturbação para a estrutura da comunidade em uma mancha remanescente (Murcia, 1995).

Para fins de análise da borda e áreasnúcleo, nesse estudo, foram admitidos dois valores de borda, ou distâncias limítrofes da borda ao interior do fragmento: o primeiro, com distância de $50 \mathrm{~m}$ e o segundo, de $100 \mathrm{~m}$. Essas duas distâncias se baseiam em estudos clássicos de borda em zoologia e botânica, utilizadas a depender do critério e objeto de análise (Paciência \& Prado, 2004). Nesse estudo foram analisadas as bordas de $50 \mathrm{~m}$ (Figura 2) e $100 \mathrm{~m}$ (Figura 3), visando observar a diversidade de cenários mediante a distância admitida, como também fornecer suporte a estudos futuros.

Alguns autores afirmam que a uma distância de 20 a $30 \mathrm{~m}$ de borda, a riqueza de espécimes vegetais arbóreos, no interior do fragmento, é restabelecida (Paciência \& Prado, 2004). Outros autores citam que, após $100 \mathrm{~m}$ para o interior do fragmento, o efeito de borda tende a minimizar seus impactos na mancha (Alves Júnior et al., 2010). 
Alguns fragmentos vegetacionais apresentaram um maior nível suscetibilidade, pelo fato de não apresentarem areas-núcleo, apenas borda, com isso a qualidade dessas manchas vegetacionais decai. Passam a exercer a função de corredores, promovendo o fluxo de espécies entre os fragmentos ou servindo como local de parada para espécies migram em busca de alimento. Estes fragmentos estão situados nos bairros, Bessa, Jardim Oceania, Cabo Branco, funcionários, Mumbaba, Gramame, Varjão, Paratibe, Mandacaru, Aeroclube e Miramar, entre outros, quer para bordas de $50 \mathrm{~m}$ (Figura 2) ou de $100 \mathrm{~m}$ (Figura 3).

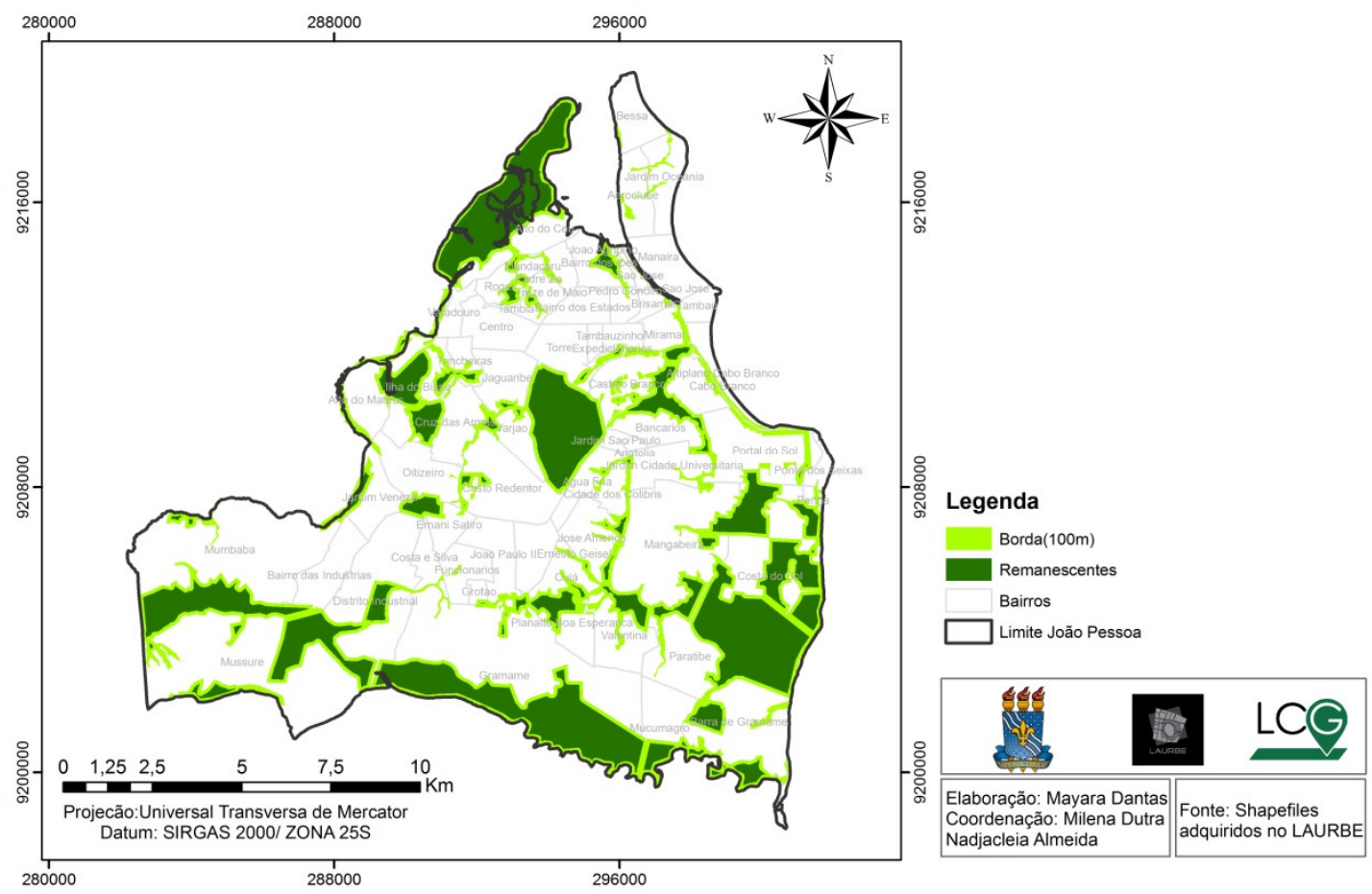

Figura 3. Distância da borda de $100 \mathrm{~m}$ para classe Vegetação Remanescente de Mata Atlântica, em João Pessoa, Paraíba, Brasil.

Kapos (1989) mostrou que a distância da penetração dos efeitos externos (por exemplo: temperatura, ventos, etc.) chega a $40 \mathrm{~m}$, a partir do limite físico do fragmento com a matriz. No entanto, é preciso levar em consideração que fragmentos que apresentam área reduzida funcionam com extensas bordas. Para tais manchas, as condições microclimáticas são fortemente influenciadas pela matriz adjacente.

\section{Índice médio de forma}

Nas manchas analisadas foram encontrados fragmentos vegetacionais com forma variada (Figura 4). para a classe vegetação remanescente foi de 2,698, correspondendo a um formato mais linear, irregular e alongado.

Um dos fragmentos, entre os 48 analisados apresentou valor do índice médio de forma analisados, apresentaram valores do índice médio de forma elevado, sendo a mancha (46), com MSI igual a 5,287. Este fragmento encontra-se inserido no bairro Jardim Oceania. Esses resultados indicam que os fragmentos apresentam-se com formas lineares e, consequentemente, sem áreas núcleo.

Formam (1995) e Grise (2008) citam que fragmentos com formas irregulares estão mais susceptíveis a apresentarem maior efeito de borda, principalmente aqueles com menor área por estar em contato direto com a matriz.

Foi observado, também, que existe uma relação direta entre os valores do índice de forma elevados e a urbanização. Isto pode ser verificado nos bairros Altiplano, Cabo Branco, Ponta do Seixas, Bessa, Aeroclube, Cristo Redentor, entre outros (Figura 4). Estes bairros, segundo pesquisas, são espaços urbanos que apresentam como atrativos do Mercado imobiliário para a moradia, as belezas paisagísticas naturais (vegetação, mar etc.), atraindo, sobretudo a classe média e alta, que busca a vendida "qualidade de vida" (Fernandes, 2013).

O fragmento da Mata do Buraquinho, apesar de ser o maior fragmento e de forma circular, situado em área urbana, é alvo de um intenso efeito de borda, sobretudo pela 
proximidade de rodovias de grande porte e fluxo intenso e das edificações no entorno.

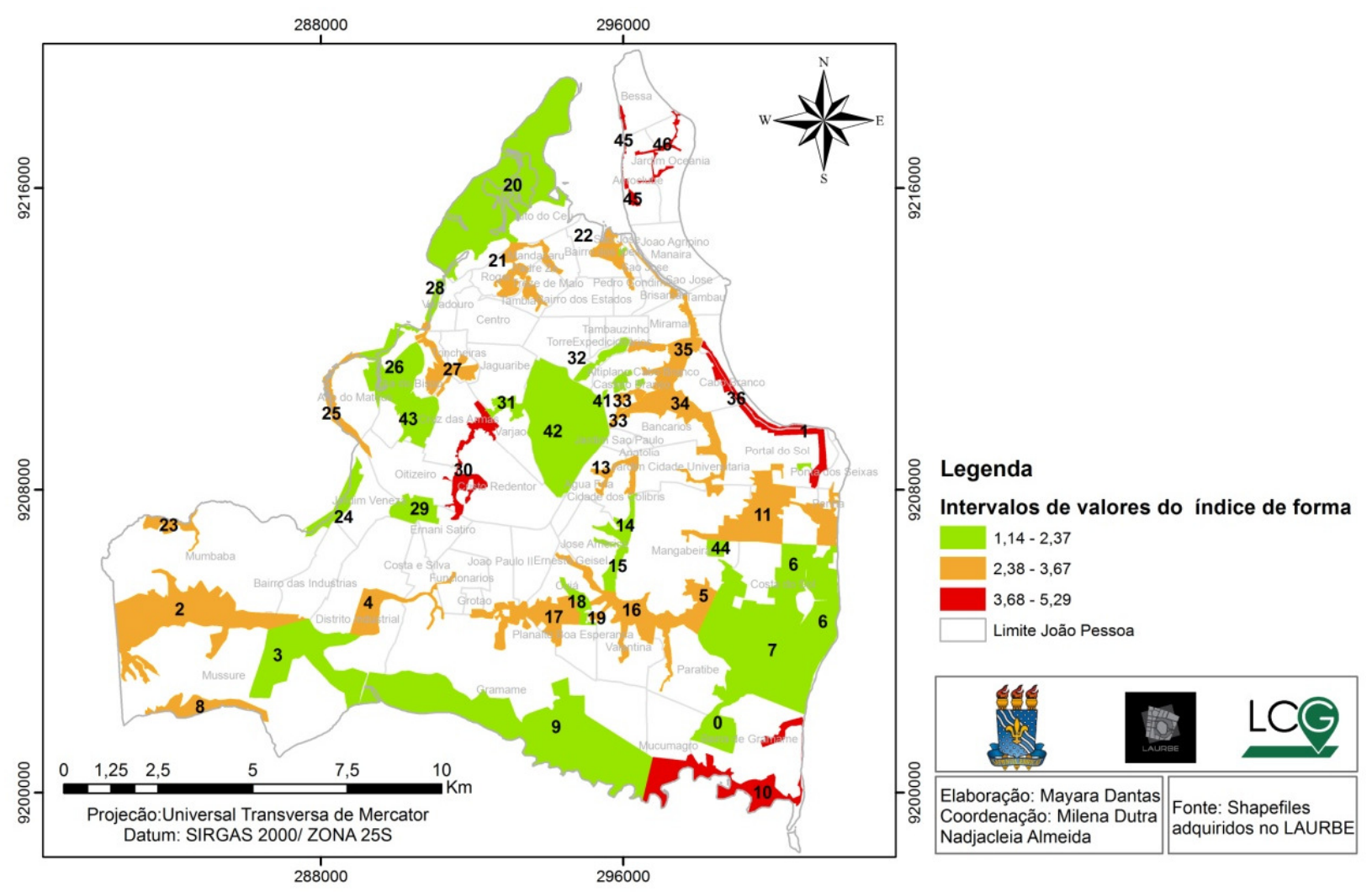

Figura 4. Intervalos de valores do Índice Médio de Forma para classe Vegetação Remanescente de Mata Atlântica, João Pessoa, Paraiba, Brasil.

Segundo Forman \& Godron (1995), são encontradas diferentes formas das manchas, o ideal, é que elas sejam o mais próximo possível da forma circular, pois esse formato minimiza relação área-borda, cujo a área central encontra-se mais distante da borda.

Quantos aos fragmentos vegetacionais que correspondem a formas com valores intermediários, e com maior representatividade no município, estão àqueles situados nos bairros Bancários, Cidade Universitária, Distrito Industrial, Valentina, Mandacaru e Roger (Figura 4).

Os fragmentos com forma mais circular destacam-se aqueles situados nos bairro Alto do céu, Costa do sol, Geisel, Mangabeira, Gramame e Jaguaribe (Figura 4).

\section{Análise da área-núcleo}

As manchas analisadas apresentaram, respectivamente, os valores de índices de áreasnúcleo (CAI) e o total de áreas núcleo remanescentes (TCCA), igual a $55,03 \%$, e 3750,5 m (Figura 4). Vale salientar que a área-núcleo corresponde aos espaços no interior do fragmento e que excetuam as áreas de borda.

Alguns fragmentos vegetacionais, situados nos bairros Jardim Oceania, Cabo Branco, funcionários, Mumbaba, Gramame, Varjão, Paratibe, Mandacaru, Aeroclube, Miramar e Ponta do Seixas entre outros, apresentaram um maior nível de fragilidade, por possuírem, entre outras características, ausência de área-núcleo e/ou áreanúcleo reduzida (Figura 5).

Tais áreas, pela elevada susceptibilidade morfológica e estrutural, configuram áreas de elevada prioridade para políticas públicas e ação mitigadoras dos impactos ambientais negativos, a exemplo do desmatamento. 

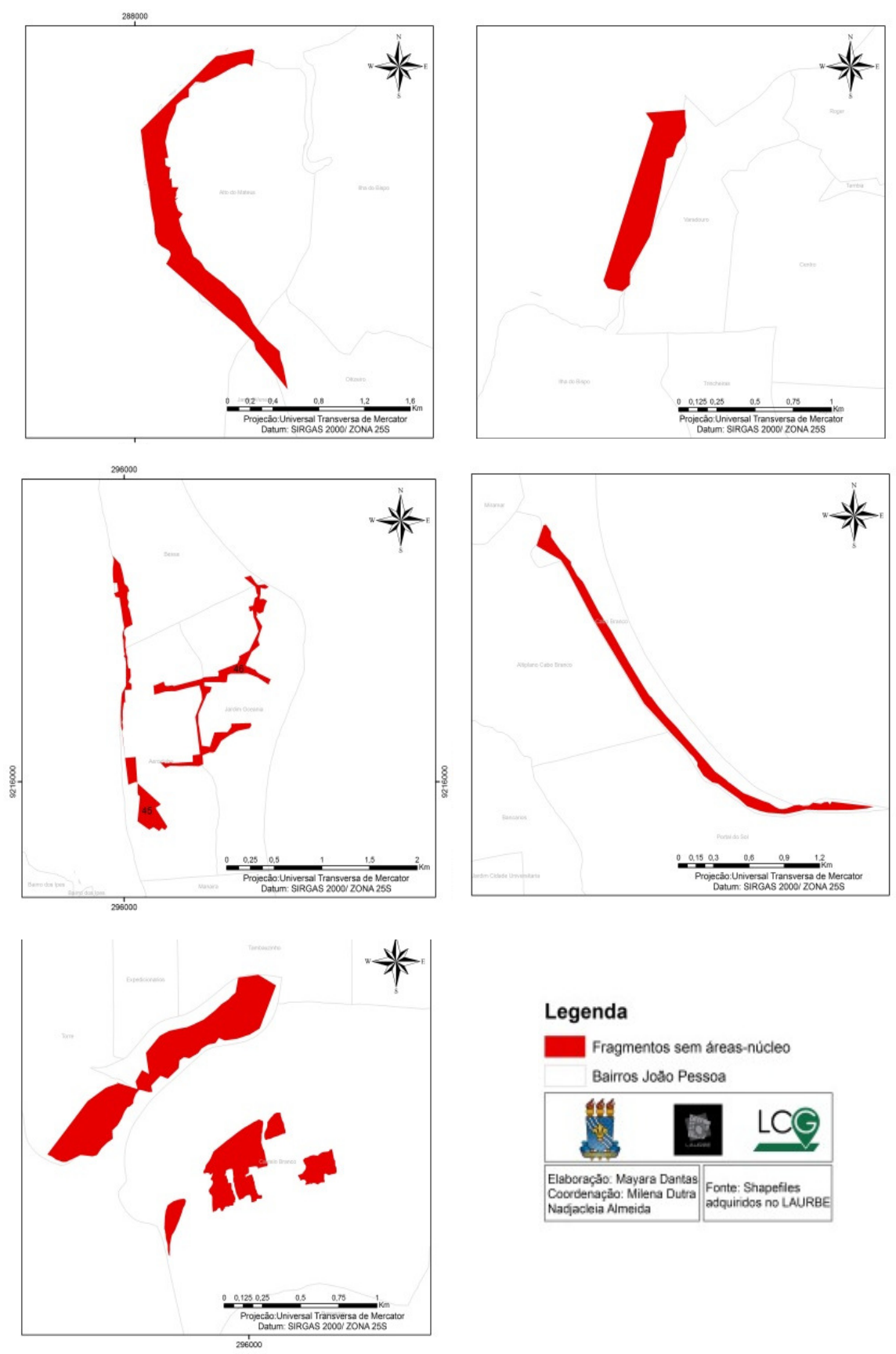

Figura 5. Fragmentos de Vegetação Remanescente de Mata Atlântica, em João Pessoa, Paraiba, Brasil, sem área-núcleo e portanto, de elevada fragilidade ambiental.

\section{Conclusão}

Os fragmentos vegetacionais de João Pessoa apresentam-se com estrutura da paisagem que apontam setores com maior grau de fragilidade ambiental, salvaguardados os maiores fragmentos vegetacionais na cidade.

No que se refere à qualidade das manchas, constatou-se que as mesmas apresentam áreas bastante reduzidas, com formatos lineares, com intenso efeito de borda nos fragmentos. Isso traz uma série de implicações pra fauna e flora desses locais, para os quais, se não forem tomadas as devidas precauções, em longo prazo, as espécies desses fragmentos tenderão a desaparecer.
Nesse sentido, assinalam-se enquanto áreas prioritárias para preservação os fragmentos vegetacionais de Mata Atlântica e/ou ecossistemas associados, sobretudo, nos bairros de Muçumagro, Ponta do Seixas, Portal do Sol, Jardim Oceania e Aeroclube, uma vez que esses fragmentos correspondem à vegetação ciliar e/ou áreas de nascentes de rios e com alto grau de fragilidade ambiental.

A metodologia adotada para este estudo, métricas da paisagem, se mostrou satisfatória considerando ser uma análise rápida para o diagnóstico da área, podendo servir de embasamento para estudos que envolvam 
diagnósticos e planejamento da paisagem para o status atual da vegetação remanescente de Mata atlântica e ecossistemas associados em João Pessoa- Paraíba.

\section{Agradecimentos}

Agradecemos ao Laboratório do Ambiente Urbano e Edificado (LAURBE/UFPB), por ceder dados vetoriais referentes à cidade de João Pessoa; e ao Grupo de Pesquisa de Estudos Geoambientais.

\section{Referências}

ANJOS, F. W. 2016. Urbanização dispersa e a transformação da paisagem natural: estudo de caso sobre a dispersão urbana na bacia do Rio Cuiá, na cidade de João Pessoa-PB, Brasil. Dissertação (Mestrado). João Pessoa, Universidade Federal da Paraíba.

BRASIL. 2012. Lei ${ }^{\circ} 12.651$, de 25 de maio.

COSTA, R. B. 2003. Fragmentação florestal e alternativas de desenvolvimento rural na região centro-oeste.1ed.UCDB, Campo Grande.

COUTO, P.,2004. Análise factorial aplicada a métricas da paisagem definidas em fragstats. Investigação Operacional, v.24, p.109-137.

CAMPANILLI, M.; SCHAUFFER, W. B. 2010 Mata Atlântica: Manual de adequação ambiental. Brasília: MMA/ SBF.

DOOLINGER, S. J.; ROSS, V. L.; PRESTON, L. A. 2002. Intellect and individuality. Creative Research Journal, v.14, n.2, p.213-226.

ECOPAISAGEM. O surgimento da ecologia de paisagens. 2014.2 Disponível: http://ecopaisagem.wikispaces.com/O+Surgiment $\mathrm{o}+\mathrm{da}+$ Ecologia+de+Paisagens. Acesso: 20/05/2014.

FERNANDES; M. A. M. 2013. A (re)produção do espaço urbano no bairro Altiplano, João Pessoa, PB: estratégias iniciativas e interesses dos agentes que produzem a cidade. Dissertação (Mestrado). João Pessoa, Centro de tecnologia, Universidade Federal da Paraíba.

FORMAN, R. T. T.; GALLI, A. E.; LECK, C. F. 1976. Forest size and avian diversity in New Jersey woodlots with some land use implications. Oecologia, v.26, p.18-8.

FORMAN, R. T. T.; GODRON, M. 1986. Landscape ecology. USA: J. Wiley.
FORMAN, R. T. T. 1995 Land mosaics. Cambridge: University Press.

GRISE, M. M. 2008. A estrutura da paisagem do mosaico de unidades de conservação do litoral norte do Paraná. Dissertação (Mestrado). Paraná, Universidade Federal do Paraná.

IBGE. Sinopse do censo Demográfico 2010. 2011. Rio de Janeiro.

JÚNIOR, A. T. F.; BRANDÃO, S. L. F. C.; ROCHA, D. K.; MARANGON, C. L.; FERREIRA, C. L. R. 2006. Efeito de borda na estrutura de espécies arbóreas em um fragmento de floresta ombrófila densa, Recife, PE, Revista Brasileira de Ciências Agrárias, v.1, n.único, p.4956.

KAPOS, V.; WANDELLI, E.; CAMARGO, J. L.; GANADE, G. 1997. Edge-related changes in environmental and plants responses due to forest fragmentation in central Amazonia. In: LAURENCE, W. F.; BIERREGAARD, R. O. (eds.). Tropical forest remnants: ecology, management, and conservation of fragmented communities.

LANG, S.; BLASCHKE, T. 2009. Análise da Paisagem com SIG. Tradução: HERMANN KUX. 1 ed. Oficina de Textos, São Paulo.

MMA.Ministério do Meio Ambiente, 2013.conceito de áreas verdes. Disponível: http//www.mma.gov.br/cidades-

sustentaveis/areas-verdes-urbanas. Acesso: 05 set. 2013.

METZGER, J. P. 2001. O que é Ecologia de Paisagens? Revista Biota Neotropica, São Paulo.

MURCIA, C. 1995. Edge effects in fragmented forests: implications for conservation. Tree, v.2, p.58-62.

NUCCI, J. C. 2007. Origem e desenvolvimento da ecologia e da ecologia de paisagem. Geografar, v.2, n.1, p.77-99.

PARAÍBA. 1985. Atlas Geográfico do Estado da Paraíba. Secretaria da Educação-Governo do Estado da Paraíba. Universidade Federal da Paraíba-UFPB. João Pessoa. Grafiset. p.100.

PACIÊNCIA, M. L.B.; PRADO, J., 2004. Efeitos de Borda sobre a comunidade de pteridófitas na 
Mata Atlântica da região de Una, sul da Bahia, Brasil. Revista Brasileira de Botânica, v.27, n.4, p.641-653.

PRIMACK, R. B.; RODRIGUES, E. 2001. Biologia da Conservação. 1 ed. E. Rodrigues, Londrina.

PORTAL SOS Mata Atlântica. Disponível: http//www.sosmataatlantica.org.br. Acesso: 02 set. 2016.

PORTO, M. L.; MENEGAT, R. 2004. Ecologia de paisagem: um novo enfoque na gestão dos sistemas da terra e do homem. In: MENEGAT, R.; ALMEIDA, G. (Orgs.) Desenvolvimento sustentavél e gestão ambiental nas cidades: estratégias a partir de Porto Alegre.ed. da UFRGS, Porto Alegre, p.361-375.

PELLEGRINO, P. R. M.; GUEDES, P. P; PIRILLO, F. C.; FERNANDES, S. A. 2006. A paisagem da borda: Uma estratégia para condução das águas da biodiversidade e das pessoas. In: COSTA, L. M. S. A. (org.). Rios e paisagens urbanos em cidades brasileiras. PROURB, Rio de Janeiro, pp.57-76.

RUDOLPHO, L. S.; BRAGHIROLLI, G.; REFOSCO, J. C.; SANTIAGO, A. G.; SABOYA, R. T. 2013. Aplicação de técnicas de geoprocessamento e métricas da paisagem na análise temporal da cobertura florestal da Bacia do Ribeirão Fortaleza em Blumenau/SC. Anais XVI Simpósio Brasileiro de Sensoriamento Remoto SBSR, Foz do Iguaçu,PR,Brasil.

SILVA, L, M, T. 2013. Planos Municipais de Conservação e Recuperação da Mata Atlântica: o pioneirismo de João Pessoa, PB. Anais do XV Enanpur. Recife: Anpur, pp.627-642.

SILVA, M. D.; CASTRO, A. A. B. C.; SILVA, B. A.; SILVA, G. J. A.; SILVEIRA, J. A. R. 2014.
Crescimento da mancha urbana na cidades de João Pessoa,PB. In: Silveira. J. A. R; Silva, M. D; Castro, A. A. B. C. (org.) Dinâmica da cidades e bordas urbanas. F\&A gráfica e editora LTDA, João Pessoa, pp.55-72.

SILVA, M. D; CLEMENTE, J. C; SILVA, G. J. A.; Almeida, N. V.; Silveira, J. A. R., 2016. Expansão urbana e periferização em cidades de porte médio: crescimento direção e velocidade. In: SILVA, G. J. A.; SILVA, M. D.; SILVEIRA, J. A. R. (org). Lugares $\mathrm{e}$ suas interfaces intraurbanas (transformações urbanas e periferização). Editora PARAIBOA, João Pessoa, p.293-320.

TURNER, M. G. 1989. Landscape ecology: the effect of pattern on process. Annual Review of Ecology and Systematics, v.20, p.171-197.

SEAGLE, S. W. 1986. Generation of species-area curves by a model of animal-habitat dynamics. In: VERNER, M. L.; MORRISSON, M. L.; RALPH, C. J. WILDLIFE 2000 - Modeling habitat relationships of terrestrial vertebrates. Madison, The University of Wisconsin, pp. 281-286.

SAUNDERS, D. A.; HOBBS, R. J.; MARGULES, C. R. 1991. Biological consequences of Ecosystem fragmentation. Conservation Biology, v.5,p.18-32.

VARJABEDIAN, R. 2010. Lei da Mata Atlântica: retrocesso ambiental. Estudos Avançados, v.24, n. 68 , p. $147-160$.

TURNER, M. G.; GARDNER, R. H. O'NEIL, R. V., 2001. Landscape ecology in theory and practice: patterns and process. Springer-Verlag, New York.

VIDOLIN, G. P.; BIONDI, D.; WANDENBRUCK, A. 2011. Análise da Estrutura da Paisagem de um Remanescente de Floresta com Araucária, Paraná, Brasil. Revista Árvore, v.35, n.3 p.515-525. 